\title{
Effect of gender affirming hormones on athletic performance in transwomen and transmen: implications for sporting organisations and legislators
}

\author{
Timothy A Roberts $\left[1\right.$, ${ }^{1}$ Joshua Smalley, ${ }^{2}$ Dale Ahrendt ${ }^{2}$
}

'Pediatrics, Children's Mercy Division of Adolescent Medicine, Kansas City, Missouri, USA ${ }^{2}$ Pediatrics, San Antonio Military Medical Center, Fort Sam Houston, Texas, USA

\section{Correspondence to} Dr Timothy A Roberts, Pediatrics, Children's Mercy Division of Adolescent Medicine, Kansas City, Missouri, USA; taroberts@cmh.edu

Accepted 28 August 2020 Published Online First

7 December 2020
Check for updates

(C) Author(s) (or their employer(s)) 2021. No commercial re-use. See rights and permissions. Published by BMJ.

To cite: Roberts TA,

Smalley J, Ahrendt D.

$\mathrm{Br} J$ Sports Med

2021:55:577-583
ABSTRACT:

Objective To examine the effect of gender affirming hormones on athletic performance among transwomen and transmen.

Methods We reviewed fitness test results and medical records of 29 transmen and 46 transwomen who started gender affirming hormones while in the United States Air Force. We compared pre- and post-hormone fitness test results of the transwomen and transmen with the average performance of all women and men under the age of 30 in the Air Force between 2004 and 2014. We also measured the rate of hormone associated changes in body composition and athletic performance.

Results Participants were 26.2 years old (SD 5.5). Prior to gender affirming hormones, transwomen performed $31 \%$ more push-ups and 15\% more sit-ups in 1 min and ran 1.5 miles $21 \%$ faster than their female counterparts. After 2 years of taking feminising hormones, the push-up and sit-up differences disappeared but transwomen were still $12 \%$ faster. Prior to gender affirming hormones, transmen performed $43 \%$ fewer push-ups and ran 1.5 miles 15\% slower than their male counterparts. After 1 year of taking masculinising hormones, there was no longer a difference in push-ups or run times, and the number of sit-ups performed in 1 min by transmen exceeded the average performance of their male counterparts.

Summary The 15-31\% athletic advantage that transwomen displayed over their female counterparts prior to starting gender affirming hormones declined with feminising therapy. However, transwomen still had a $9 \%$ faster mean run speed after the 1 year period of testosterone suppression that is recommended by World Athletics for inclusion in women's events.

\section{BACKGROUND}

Most competitive sports segregate male and female athletes due to biologic differences between the sexes. Because exposure to testosterone in males leads to physiologic advantages in strength and endurance, female sports need to be a protected category to ensure fairness in competition. ${ }^{1}$ Questions arise then as to which category a transgender athlete competes in and how society balances benefits to the athlete of sports participation in their experienced gender with perceptions of fairness to other athletes. ${ }^{2-5}$ Supraphysiologic doses of androgens have a positive effect on athletic performance. ${ }^{6}$ However, gender affirming hormones have an unknown effect on athletic performance among transgender individuals during gender transition, making it difficult to develop guidelines for transgender inclusion in sports. Several guidelines for inclusion of transgender athletes in elite international or professional sports exist but they are based on limited research. ${ }^{8} 9$ The World Athletics (IAAF) and the International Olympic Committee (IOC) created guidelines requiring female athletes to demonstrate suppression of testosterone levels to less than 5-10 nmol/L for at least 12 months prior to competing in women's events. However, athletes have challenged the section of these guidelines applying to women with disorders of sexual development and other causes of hyperandrogenism, citing a lack of supporting evidence, which calls these guidelines into question. ${ }^{10} 11$

Gender affirming administration of testosterone in transmen decreases adiposity, and increases muscle mass, thigh muscle volume, haemoglobin, grip strength and thigh strength. ${ }^{9}$ 12-14 Gender affirming blockage of testosterone and administration of oestrogen in transwomen (oestrogen) has the opposite effect, but transwomen retain an advantage in muscle mass, volume, and strength over female controls after 1 year on oestrogen. ${ }^{914-17}$ Most changes in body composition occur within the first year on testosterone or oestrogen, with slower changes after that time. ${ }^{91618-20}$

How do these body composition changes affect athletic performance? A retrospective review of self-reported run times among eight transwomen runners found an overall decline in times collected months to years before and after starting oestrogen but not in the runners' performance relative to runners of the same age and gender. No other studies have examined the effect of testosterone or oestrogen on athletic performance. ${ }^{21}$

We conducted this study to examine the effect of gender affirming hormones on body composition and athletic performance among transgender individuals to help improve future guidelines for transgender inclusion in sporting competition.

\section{METHODS}

\section{Study population}

This was a retrospective review of medical records and fitness tests results from 222 self-identified military personnel who filed a request to begin gender transition or continue testosterone or oestrogen while serving in the United States Air Force (Air Force).

\section{Patient involvement}

The idea for this study arose from our discussions with servicemembers seen in the Air Force 
Transgender Clinic about the effect of testosterone or oestrogen on body composition and athletic performance on the Air Force physical fitness assessment. We did not know how to advise them based on the medical literature. We conducted this study to address this concern.

\section{Demographic variables}

We recorded the servicemember's age, service branch, military rank, gender assigned at birth, date testosterone or oestrogen started, type of testosterone or oestrogen used and days between starting testosterone or oestrogen and the first serum hormone level in the adult range recorded in the military electronic medical record. For transwomen, we also recorded the days between starting oestrogen and the first laboratory test indicating suppression of endogenous testosterone. We had incomplete records of testosterone or oestrogen obtained outside the military healthcare system.

\section{Outcome measures}

The Air Force requires servicemembers to participate in a physical fitness assessment every 12 months, including measurement of height, weight, waist circumference, number of push-ups and sit-ups performed in $1 \mathrm{~min}$ each, and time required to run 1.5 miles. The Air Force uses these tests to assess suitability for promotion, inclusion in specialised programmes and retention in the military service. The Air Force requires servicemembers to participate in all events unless a medical provider grants them a waiver for participation in a specific event secondary to a medical condition. Servicemembers with a waiver for a portion of the assessment must retake the assessment every 6 months. Enlisted servicemembers engage in regular group exercise. However, the type and intensity of training vary by occupation. The Air Force requires servicemembers who fail to meet physical fitness standards to attend additional physical training sessions outside of normal work hours until they can meet the fitness requirements or leave military service.

We assessed pretreatment fitness using the most recent score from each event on the physical fitness assessment prior to starting testosterone or oestrogen. We assessed post-treatment fitness using all fitness test scores occurring in the first 30 months after starting testosterone or oestrogen. We also recorded the time elapsed between starting testosterone or oestrogen and the occurrence of each event. The primary outcome for this study was change in fitness assessment score between the pre-hormone assessment and post-hormone assessment.

We used the results of the Air Force fitness tests performed by men ( $>2.3$ million) and women $(>567000)$ under the age of 30 between 2004 and 2014 as a proxy for average performance among men (CM) and women (CW) in the Air Force. ${ }^{22}$ We used the results of all fitness tests performed by men $(>3.5$ million) and women (>777 000) in the Air Force between 2004 and 2014 as a proxy for height and weight among men (CM) and women $(\mathrm{CW})$ in the Air Force. ${ }^{22}$

\section{Statistical analysis}

We used generalised linear mixed models with a first order autoregressive repeated covariance type in SPSS V.24 to assess the association of hormonal therapy with changes in physical fitness assessment scores. We selected this analysis method to account for correlation between repeated measures, variable number of follow-up assessments, variable follow-up times and missing data points for each participant. From this analysis we obtained an estimated mean of push-ups performed in $1 \mathrm{~min}$,

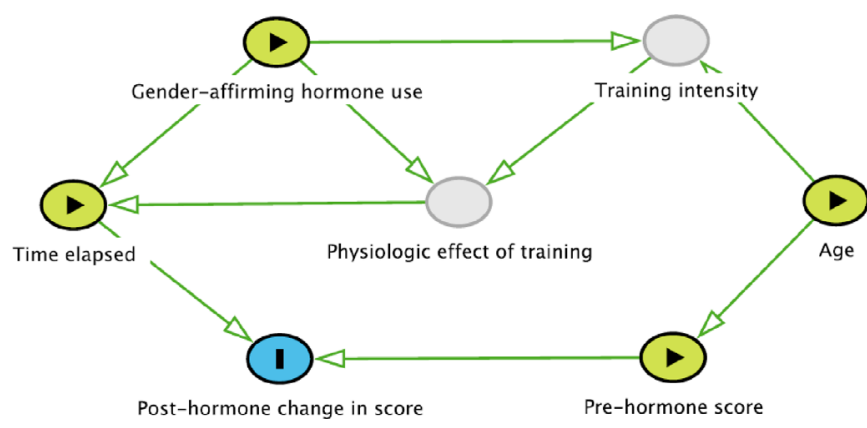

Figure 1 Directed acyclic graph of our multivariable model. Pre-hormone score: the results of the most recent physical fitness assessment prior to starting gender affirming therapy. Age: age in years when starting gender affirming hormone therapy. Training intensity: type and amount of exercise performed by the servicemember. Physiologic effect of training: effect of training performed on the servicemember's strength and endurance. Time elapsed: time interval (months) between starting gender affirming hormone therapy and the assessment of physical performance. Post-hormone change in score: change in push-ups, sit-ups and run times between the pre-hormone assessment and the current assessment (primary study outcome).

sit-ups performed in $1 \mathrm{~min}$ and 1.5 mile run times for transmen and transwomen before testosterone or oestrogen, between 0 and 1 years on testosterone or oestrogen, 1-2 years on testosterone or oestrogen and over 2 years on testosterone or oestrogen. We then compared these results with the average performance of $\mathrm{CM}$ and $\mathrm{CW}$.

We conducted a multivariable assessment of the association between months on gender affirming hormones and changes from pre-testosterone or oestrogen fitness after adjusting for pre-testosterone or oestrogen performance and age at initiation of testosterone or oestrogen. Figure 1 is a directed acyclic graph representing the conceptual model underlying our multivariable model. Our null hypothesis for this model is that testosterone and oestrogen are not associated with a subsequent change in athletic performance for any length of testosterone or oestrogen use or pre-testosterone or oestrogen athletic performance. We performed analyses separately for transmen and transwomen.

\section{RESULTS}

Research participant characteristics

Two hundred and twenty-two servicemembers self-identified as transgender in 2016-2018 and filed a request to begin or continue gender affirming care while serving in the Air Force. We excluded 147 of these participants for the following reasons: 28 had not started testosterone or oestrogen, 3 were on testosterone or oestrogen but did not have a start date available, 99 did not have pre-testosterone or oestrogen physical assessment scores available and 16 did not have any post-testosterone or oestrogen physical assessment scores available. We included the remaining 29 transmen and 46 transwomen in our study. (table 1) The mean age of our sample was 26.2 years (SD 5.5) with a median age of 25 years (range 19-46). The majority $(78.3 \%$ ) of our participants were <age 30 when they began testosterone or oestrogen. Among CM, mean height was $178.2 \mathrm{~cm} \mathrm{(6.8)} \mathrm{and}$ weight was $83.5 \mathrm{~kg}(12.0)$. Among CW, mean height was 164.4 $\mathrm{cm}$ (6.4) and weight was $65.7 \mathrm{~kg}(9.8)$.

The baseline physical fitness assessment occurred an average of $144.4 \pm 101.4$ days before starting testosterone or oestrogen. We followed participants for an average of 394.0 288.2 days after they started testosterone or oestrogen. Participants 


\begin{tabular}{|c|c|c|}
\hline \multirow{2}{*}{$\begin{array}{l}\text { Pretreatment demographics and body } \\
\text { composition }\end{array}$} & Transwomen $(n=46)$ & $\begin{array}{l}\text { Transmen } \\
(\mathrm{n}=29)\end{array}$ \\
\hline & Mean (SD) & Mean (SD) \\
\hline $\begin{array}{l}\text { Age at initiation of gender affirming } \\
\text { hormones (years) }\end{array}$ & $26.6(4.8)$ & $25.6(6.6)$ \\
\hline Height (cm) & $176.3(7.1)$ & $165.6(5.3)$ \\
\hline Weight (kg) & 76.7 (12.6) & $69.5(10.0)$ \\
\hline Body mass index $\left(\mathrm{kg} / \mathrm{m}^{2}\right)$ & $24.4(3.7)$ & $25.3(3.3)$ \\
\hline Waist circumference $(\mathrm{cm})$ & $80.8(8.4)$ & $76.7(8.9)$ \\
\hline \multicolumn{3}{|l|}{ Rank (\%) } \\
\hline Enlisted & 100 & 93.10 \\
\hline Officer & & 6.90 \\
\hline \multicolumn{3}{|l|}{ Duty status (\%) } \\
\hline Active duty & 95.70 & 86.20 \\
\hline Reserves & 2.20 & 6.90 \\
\hline Air National Guard & 2.20 & 6.90 \\
\hline
\end{tabular}

had an average of $2.2 \pm 0.9$ assessments after starting testosterone or oestrogen (median 2, range 1-4). Among transmen, two participants were medically excused from the push-up assessment during the follow-up period, and 11 were excused from the run. Among transwomen, two were excused from the push-up assessment, one from the sit-up assessment, and four from the run. Details of the testosterone or oestrogen prescribed and time to first therapeutic hormone levels are listed in table 2 .

Effect of gender affirming hormones on body composition and athletic performance

Tables $3-5$ and figure 2 provide a summary of changes in patient outcomes while on testosterone or oestrogen. In multivariable analyses, including baseline performance, age at initiation of testosterone or oestrogen, and months on testosterone or oestrogen, we rejected the null hypothesis. In our analyses, a higher baseline score was associated with a greater decline (or smaller increase) in score at follow-up for all outcomes except for 1.5 mile run time among transwomen, where baseline run time had no effect on the changes observed at follow-up (data not shown). Age at initiation of testosterone or oestrogen had no significant effect on outcomes (data not shown). For transwomen, time on oestrogen was associated with an increase in weight (table 3)
Table 3 Effect of gender affirming hormones on weight and waist circumference

\begin{tabular}{|c|c|c|}
\hline \multirow[b]{2}{*}{ Weight (kg) } & Transwomen & Transmen \\
\hline & Mean $(95 \% \mathrm{Cl})$ & Mean $(95 \% \mathrm{Cl})$ \\
\hline \multicolumn{3}{|c|}{ Time on gender affirming hormones } \\
\hline Pretreatment & 76.7 (73.3 to 80.2$)$ & 69.5 (66.0 to 72.9$)$ \\
\hline $0-1$ years & 75.6 (72.1 to 79.1$)$ & 72.1 (68.6 to 75.5$)$ \\
\hline $1-2$ years & 77.1 (73.4 to 80.9$)$ & 71.1 (67.4 to 74.8$)$ \\
\hline \multirow[t]{2}{*}{$2-2.5$ years } & 76.7 (70.8 to 82.6$)$ & 70.0 (65.8 to 74.2$)$ \\
\hline & $\boldsymbol{\beta}(95 \% \mathrm{Cl})$ & $\boldsymbol{\beta}(95 \% \mathrm{Cl})$ \\
\hline $\begin{array}{l}\text { Change in weight per month } \\
\text { on hormones* }\end{array}$ & $0.15(0.04$ to 0.25$)$ & $-0.07(-0.21$ to 0.06$)$ \\
\hline Waist circumference (cm) & Mean $(95 \% \mathrm{Cl})$ & Mean $(95 \% \mathrm{Cl})$ \\
\hline \multicolumn{3}{|c|}{ Time on gender affirming hormones } \\
\hline Prereatment & 80.8 (78.7 to 82.8$)$ & 76.7 (74.2 to 79.2$)$ \\
\hline $0-1$ years & $79.0(77.0$ to 81.0$)$ & 79.2 (76.5 to 81.8$)$ \\
\hline $1-2$ years & 78.9 (76.2 to 81.5$)$ & 78.5 (75.2 to 81.8$)$ \\
\hline \multirow[t]{2}{*}{$2-2.5$ years } & 82.0 (76.5 to 87.5$)$ & 78.4 (74.4 to 82.3$)$ \\
\hline & $\boldsymbol{\beta}(95 \% \mathrm{Cl})$ & $\boldsymbol{\beta}(95 \% \mathrm{Cl})$ \\
\hline $\begin{array}{l}\text { Change in waist per month on } \\
\text { hormones* }\end{array}$ & $0.05(-0.08$ to 0.18$)$ & $-0.03(-0.15$ to 0.10$)$ \\
\hline $\begin{array}{l}\text { All analyses adjusted for variati } \\
\text { participant. } \\
{ }^{*} \text { Adjusted for pretreatment me } \\
\text { hormones. }\end{array}$ & $n$ the number of $m$ & ents per research \\
\hline
\end{tabular}

and a decline in athletic performance (table 4 and figure 2). For transmen, time on testosterone had no effect on body composition (table 3) but was associated with an improvement in athletic performance (table 5 and figure 2). Prior to treatment, transwomen were heavier than $\mathrm{CW}$ (mean difference $11.0 \mathrm{~kg}, 95 \%$ CI 7.6 to 14.4$)$ and lighter than CM (-6.8 $\mathrm{kg},-10.2$ to -3.4$)$. Transmen were lighter than CM $(-14.0$ $\mathrm{kg},-17.5$ to -10.5$)$ and heavier than $\mathrm{CW}(3.8 \mathrm{~kg}, 0.3$ to 7.3). Both transwomen and transmen maintained these differences over the first 2.5 years on testosterone or oestrogen (data not shown).

Athletic performance among transgender servicemembers Prior to oestrogen, transwomen performed fewer push-ups in $1 \mathrm{~min}$ than $\mathrm{CM}$ and this gap increased with oestrogen. Transwomen performed more push-ups than CW prior to oestrogen but this difference disappeared after 2 years on

\section{Table 2 Gender affirming hormones prescribed}

\begin{tabular}{|c|c|c|}
\hline & Transwomen $(n=46)$ & Transmen $(n=29)$ \\
\hline Gender affirming hormones prescribed & $\begin{array}{l}\text { Oral oestradiol: } 67.4 \% \\
\text { Transdermal oestradiol: } 15.2 \% \\
\text { Oestradiol valerate IM: } 13.0 \% \\
\text { Oestradiol cypionate IM: } 2.2 \% \\
\text { Unknown: } 2.2 \%\end{array}$ & $\begin{array}{l}\text { Testosterone cypionate: } 89.7 \% \\
\text { Testosterone enanthate: } 3.4 \% \\
\text { Transdermal testosterone: } 3.4 \% \\
\text { Testosterone 2\% gel: } 3.4 \%\end{array}$ \\
\hline $\begin{array}{l}\text { Time to first therapeutic level ( } 39 \text { transwomen, } 26 \\
\text { transmen) (days) (median (range)) }\end{array}$ & $234.0(27-1270)$ & $98.5(23-1116)$ \\
\hline Testosterone blockade prescribed (transwomen only) & $\begin{array}{l}\text { Spironolactone: } 80.4 \% \\
\text { Spironolactone and finasteride: } 13.0 \% \\
\text { GnRH agonist IM: } 2.2 \% \\
\text { GnRH agonist and spironolactone: } 2.2 \% \\
\text { Unknown: } 2.2 \%\end{array}$ & \\
\hline $\begin{array}{l}\text { Time to first documented suppression ( } \mathrm{n}=35 \text { ) (days) } \\
\text { (median (range)) }\end{array}$ & $200(27-979)$ & \\
\hline
\end{tabular}

\footnotetext{
$\mathrm{GnRH}$, gonadotropin releasing hormone.
} 
Original research

Table 4 Effect of gender affirming hormones on athletic performance among transwomen

\begin{tabular}{|c|c|c|c|}
\hline Push-ups in $1 \mathrm{~min}$ & Mean $(95 \% \mathrm{Cl})$ & $\begin{array}{l}\text { Mean difference transwomen vs CW } \\
(95 \% \mathrm{Cl})\end{array}$ & $\begin{array}{l}\text { Mean difference transwomen vs } \mathrm{CM} \\
(95 \% \mathrm{Cl})\end{array}$ \\
\hline \multicolumn{4}{|l|}{ Time on hormones } \\
\hline Pretreatment & $47.3(44.6$ to 50.0$)$ & $14.8(12.1$ to 17.4$)$ & $-6.2(-8.9$ to -3.6$)$ \\
\hline $0-1$ years & $44.6(41.8$ to 47.4$)$ & $12.1(9.3$ to 14.8$)$ & $-8.9(-11.7$ to -6.1$)$ \\
\hline $1-2$ years & $43.2(39.3$ to 47.1$)$ & 10.7 (6.8 to 14.5$)$ & $-10.3(-14.2$ to -6.5$)$ \\
\hline \multirow[t]{2}{*}{$2-2.5$ years } & 34.6 (26.1 to 43.1$)$ & $2.1(-6.4$ to 10.5$)$ & $-18.9(-27.3$ to -10.5$)$ \\
\hline & $\boldsymbol{\beta}(95 \% \mathrm{Cl})$ & & \\
\hline Change in push-ups per month on hormones* & $-0.38(-0.63$ to -0.13$)$ & & \\
\hline Sit-ups in $1 \mathrm{~min}$ & Mean $(95 \% \mathrm{Cl})$ & & \\
\hline \multicolumn{4}{|l|}{ Time on hormones } \\
\hline Pretreatment & 53.5 (51.3 to 55.7$)$ & $7.9(5.7$ to 10.0$)$ & $1.1(-1.7$ to 3.2$)$ \\
\hline $0-1$ years & 54.1 (51.9 to 56.3$)$ & $8.5(6.3$ to 10.7$)$ & $1.7(-0.5$ to 3.9$)$ \\
\hline $1-2$ years & $51.8(48.6$ to 55.0$)$ & 6.2 (3.0 to 9.3$)$ & $-0.6(-3.8$ to 2.5$)$ \\
\hline \multirow[t]{2}{*}{$2-2.5$ years } & 44.8 (37.1 to 52.4$)$ & $-0.9(-8.4$ to 6.7$)$ & $-7.7(-15.2$ to -0.1$)$ \\
\hline & $\boldsymbol{\beta}(95 \% \mathrm{Cl})$ & & \\
\hline Change in sit-ups per month on hormones* & $-0.37(-0.58$ to -0.15$)$ & & \\
\hline 1.5 mile run time $(\mathrm{s})$ & Mean $(95 \% \mathrm{Cl})$ & & \\
\hline \multicolumn{4}{|l|}{ Time on hormones } \\
\hline Pretreatment & 708 (681 to 734$)$ & $-147(-173$ to -121$)$ & $-12(-38$ to 14$)$ \\
\hline $0-1$ years & 758 (731 to 786$)$ & $-97(-124$ to -70$)$ & $39(12$ to 65$)$ \\
\hline $1-2$ years & 791 (753 to 829$)$ & $-64(-101$ to -26$)$ & 72 (34 to 109$)$ \\
\hline \multirow[t]{2}{*}{$2-2.5$ years } & 765 (685 to 846$)$ & $-90(-169$ to -10$)$ & $45(-34$ to 125$)$ \\
\hline & $\boldsymbol{\beta}(95 \% \mathrm{Cl})$ & & \\
\hline Change in run time per month on hormones* & $2.9(0.5$ to 5.3$)$ & & \\
\hline
\end{tabular}

All analyses adjusted for variation in the number of measurements per research participant.

CW, average performance on Air Force physical fitness tests by females $<30$ years old conducted between 2004 and $2014 .^{22}$

$\mathrm{CM}$, average performance on Air Force physical fitness tests by males <30 years old conducted between 2004 and $2014{ }^{22}$

${ }^{*}$ Adjusted for pretreatment measurements and age when started gender affirming hormones.

oestrogen (table 4 and figure 2). Prior to oestrogen there was no difference in sit-ups performed in 1 min among transwomen compared with CM but there was a difference with CW. After 2 years on oestrogen, transwomen performed fewer sit-ups than CM, but the difference with CW had disappeared (table 4 and figure 2). Run times among transwomen were similar to times among CM and faster than times among CW prior to oestrogen. Run times worsened among transwomen after starting oestrogen and became slower than times in CM but remained faster than CW at all time points (table 4 and figure 2).

Transmen performed more push-ups in 1 min than CW prior to testosterone and this gap increased with testosterone. Transmen performed fewer push-ups than CM prior to testosterone but this gap closed after 1 year on testosterone (table 5, figure 2). Transmen consistently performed more situps than CW before and after testosterone. Transmen and CM completed a similar number of sit-ups in $1 \mathrm{~min}$ prior to starting testosterone, and transmen performance exceeded that of CM after 1 year on testosterone. There was no difference in 1.5 mile run times between transmen and CW prior to testosterone, but transmen were faster after 1 year on testosterone. Transmen were slower than CM prior to testosterone but had closed the time gap after 1 year (table 5 and figure 2).

\section{DISCUSSION}

In this study, we assessed the effects of gender affirming hormones on transgender individuals over time by means of a standardised test in a non-laboratory setting. Athletic performance improved among transmen and declined among transwomen. Among transwomen, competitive advantages from the effects of prior testosterone exposure continued beyond the 12 month standard currently proposed for inclusion in women's elite competition. ${ }^{10}$ This finding suggests that governing bodies for sporting competition should require more than 1 year of testosterone suppression prior to competition when creating guidelines for inclusion of transwomen in women's elite athletics.

\section{Study findings and prior research}

Like previous studies, our study showed an association between testosterone and increased strength among transgender men. ${ }^{1317}$ We confirmed the decrease in strength associated with oestrogen in transgender women that was found in some studies, ${ }^{14-16}$ but not others. ${ }^{17}$ Unlike several of these previous studies, our measures of muscular strength assessed repeated submaximal efforts (push-ups and sit-ups) over a $1 \mathrm{~min}$ period as opposed to a single maximal effort. Our results capture differences in both endurance and strength rather than just strength and probably have more relevance to sports that require sustained effort over time rather than single explosive efforts like power lifting. Our assessments of muscular strength are also confounded by differences in weight between our transgender participants and reference populations. For example, as a group, transwomen weigh more than CW. Thus transwomen will have a higher power output than CW when performing an equivalent number of push-ups. Therefore, our study may underestimate the 
Table 5 Effect of gender affirming hormones on athletic performance among transmen

\begin{tabular}{|c|c|c|c|}
\hline Push-ups in $1 \mathrm{~min}$ & Mean $(95 \% \mathrm{Cl})$ & $\begin{array}{l}\text { Mean difference transmen vs CW } \\
(95 \% \mathrm{Cl})\end{array}$ & $\begin{array}{l}\text { Mean difference transmen vs CM } \\
(95 \% \mathrm{Cl})\end{array}$ \\
\hline \multicolumn{4}{|l|}{ Time on hormones } \\
\hline Pretreatment & $37.4(33.2$ to 41.5$)$ & $4.8(0.7$ to 9.0$)$ & $-16.1(-20.3$ to -12.0$)$ \\
\hline $0-1$ years & $44.8(40.5$ to 49.0$)$ & $12.2(8.1$ to 16.4$)$ & $-8.7(-12.9$ to -4.6$)$ \\
\hline $1-2$ years & $51.8(46.2$ to 57.5$)$ & 19.3 (13.8 to 24.8$)$ & $-1.7(-7.2$ to 3.9$)$ \\
\hline \multirow[t]{2}{*}{$2-2.5$ years } & 56.1 (49.9 to 62.4$)$ & 25.6 (19.4 to 31.8$)$ & $4.6(-6.4$ to 10.5$)$ \\
\hline & $\beta(95 \% \mathrm{Cl})$ & & \\
\hline Change in push-ups per month on hormones* & $0.46(0.22$ to 0.70$)$ & & \\
\hline Sit-ups in $1 \mathrm{~min}$ & Mean $(95 \% \mathrm{Cl})$ & & \\
\hline \multicolumn{4}{|l|}{ Time on hormones } \\
\hline Pretreatment & 50.4 (47.4 to 53.4$)$ & $4.8(1.8$ to 7.7$)$ & $-2.0(-4.9$ to 0.9$)$ \\
\hline $0-1$ years & 52.8 (49.8 to 55.8$)$ & $7.2(4.2$ to 10.2$)$ & $0.4(-2.6$ to 3.4$)$ \\
\hline $1-2$ years & $58.2(54.0$ to 62.3$)$ & $12.5(8.5$ to 16.6$)$ & 5.7 (1.7 to 9.8$)$ \\
\hline \multirow[t]{2}{*}{$2-2.5$ years } & $58.3(53.8$ to 62.8$)$ & $12.7(8.2$ to 17.1$)$ & 5.9 (1.4 to 10.3$)$ \\
\hline & $\boldsymbol{\beta}(95 \% \mathrm{Cl})$ & & \\
\hline Change in sit-ups per month on hormones* & 0.32 (0.16 to 0.49 ) & & \\
\hline 1.5 mile run time $(\mathrm{s})$ & Mean $(95 \% \mathrm{Cl})$ & & \\
\hline \multicolumn{4}{|l|}{ Time on hormones } \\
\hline Pretreatment & 850 (802 to 899$)$ & $-4(-52$ to 43$)$ & 131 (83 to 178$)$ \\
\hline $0-1$ years & 826 (776 to 876$)$ & $-29(-78$ to 20$)$ & 106 (57 to 155$)$ \\
\hline $1-2$ years & 751 (687 to 815$)$ & $-104(-167$ to -41$)$ & $31(-32$ to 94$)$ \\
\hline \multirow[t]{2}{*}{$2-2.5$ years } & 711 (640 to 783$)$ & $-144(-214$ to -74$)$ & -9 (-79 to 61$)$ \\
\hline & $\boldsymbol{\beta}(95 \% \mathrm{Cl})$ & & \\
\hline Change in run time per month on hormones* & $-3.2(-5.3$ to -1.2$)$ & & \\
\hline
\end{tabular}

All analyses adjusted for variation in the number of measurements per research participant.

CW, average performance on Air Force physical fitness tests by females aged <30 years conducted between 2004 and $2014{ }^{22}$

CM, average performance on Air Force physical fitness tests by males aged <30 years conducted between 2004 and 2014 . $^{22}$

${ }^{*}$ Adjusted for pretreatment measurements and age when started gender affirming hormones.

advantage in strength that transwomen have over CW. Further studies are needed to determine if the changes we saw in our study also apply to measures of explosive strength. Participants' exercise intentions or training habits were unknown, making it difficult to determine the aetiology of the pretreatment differences in push-up performance between transgender servicemembers and all servicemembers under the age of 30 in the Air Force. It is possible that transmen performed exercises to increase upper body muscle mass in order to give them a more masculine appearance and decrease their gender dysphoria while also improving push-up performance relative to CW. Gender dysphoria could stimulate the opposite behaviour in transwomen, decreasing push-up performance and explaining why transwomen performed fewer push-ups than CM prior to starting oestrogen. Differences in exercise habits could also influence the relationship between athletic performance and testosterone or oestrogen examined in this study. However, without the information on strength training it is impossible to make any definitive determinations.

Transmen also performed more sit-ups in $1 \mathrm{~min}$ than $\mathrm{CW}$ prior to starting testosterone. This difference in sit-up performance may also reflect a behavioural response to gender dysphoria among transmen. There was no difference between transmen and CM in sit-up performance. Unlike the increased size of upper body musculature associated with push-ups, a flat and toned appearing abdomen is seen as a positive attribute for achieving an ideal masculine or feminine appearance, making it less likely that transwomen would avoid this exercise type at a greater rate than CM.
In addition, we demonstrated a worsening of run times associated with oestrogen among transwomen that was seen in a previous study using a smaller sample and self-reported data. ${ }^{21}$ Testosterone exposure is associated with an increase in muscle volume and blood haemoglobin content, producing most of the ergogenic effects. ${ }^{1}$ The improvement in run times seen among transmen with exposure to testosterone and the decline among transwomen undergoing testosterone blockade demonstrates this ergogenic effect of testosterone. However, exposure to testosterone during puberty results in sex differences in height, pelvic architecture and leg bones in the lower limbs that confer an athletic advantage to males after puberty. ${ }^{1}$ These anatomical differences do not respond to changes in testosterone exposure among post-pubertal adults. These pretreatment anatomical differences may explain why transwomen retained an advantage in 1.5 mile run times over CW after beginning oestrogen as an adult, while push-up and sit-up performance, which are less influenced by differences in skeletal architecture, declined to the level of CW after 2 years on oestrogen. It is possible that these results could be different among transwomen who begin gender affirming hormone therapy shortly after the onset of puberty and never experienced the ergogenic benefits of testosterone exposure. Further research is required to determine if the effects of testosterone or oestrogen on athletic performance vary by level of pubertal development at the time of initiating testosterone or oestrogen and if guidelines for transgender inclusion in sports need to account for the athlete's pubertal stage when testosterone or oestrogen began. 
Push-Ups Performed in 1-minute

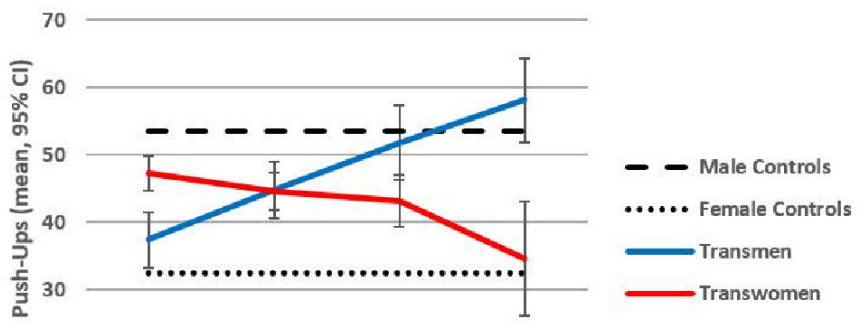

20

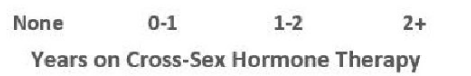

Sit-Ups Performed in 1-minute

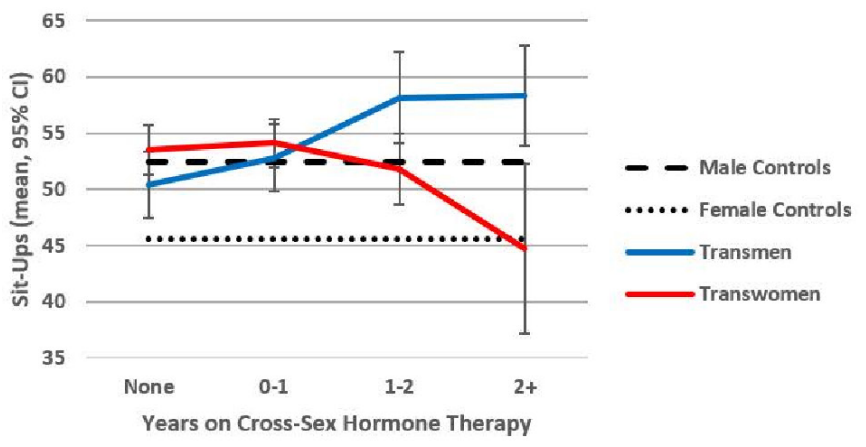

1.5-mile Run

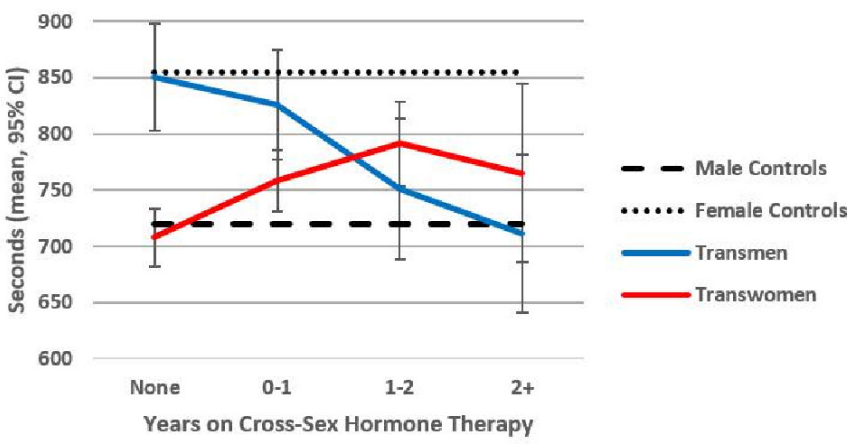

Figure 2 Gender affirming therapy and athletic performance. Male controls line represents the average performance on over 2.3 million Air Force physical fitness tests performed by males under the age of 30 between 2004 and $2014 .^{22}$ Female controls line represents the average performance on over 567000 Air Force physical fitness tests performed by females under the age of 30 between 2004 and $2014 .{ }^{22}$

\section{What are the new findings?}

- Transwomen retain an advantage in upper body strength (push-ups) over female controls for 1-2 years after starting gender affirming hormones.

- Transwomen retain an advantage in endurance (1.5 mile run) over female controls for over 2 years after starting gender affirming hormones.

- Transwomen are currently mandated to have 1 year of testosterone suppression before being permitted to compete at the elite level. This may be too short if the aim is a level playing field.
Study limitations and future directions

The strengths of this study include a larger sample size than previous studies, a longer follow-up period and a focus on performance on a standardised fitness test rather than isolated muscle strength. This study has limitations as well. The lack of a longitudinal control group not on testosterone or oestrogen makes changes in performance due to the passage of time a potential confounding factor. The high variability in time between baseline assessment and starting testosterone or oestrogen could also confound our assessment of the effect of time on testosterone or oestrogen. However, the uniformity of the data showing improvement in performance scores in transmen and the decline in transwomen makes it unlikely that the changes in performance are random or can be attributed to changes over time alone. The conceptual model for our multivariable analysis could be wrong and incorrectly estimate the relationship of testosterone or oestrogen with changes in athletic performance. Finally, testosterone and oestrogen protocols were not standardised for our participants. Variations in hormonal exposure between patients could confound our measurement of the effects of testosterone or oestrogen on athletic performance and body composition. Most participants had documentation of therapeutic hormone levels and suppression of testosterone, suggesting dosing at physiologic levels, although the time between starting testosterone or oestrogen and documentation of physiologic levels varied widely between participants. We do not know to what extent this variability represents differences in medication dosing or inadequate access to medical records from outside the military healthcare system. Future studies should address these limitations. Development of evidence based guidelines for transgender inclusion in elite athletic competition by governing bodies for athletics, such as the IOC and World Athletics, requires further research to define the timing of changes associated with testosterone or oestrogen.

\section{CONCLUSION}

In this study, we confirmed that use of gender affirming hormones are associated with changes in athletic performance and demonstrated that the pretreatment differences between transgender and cis gender women persist beyond the 12 month time requirement currently being proposed for athletic competition by the World Athletics and the IOC. ${ }^{10}$ This study suggests that more than 12 months of testosterone suppression may be needed to ensure that transgender women do not have an unfair competitive advantage when participating in elite level athletic competition.

Acknowledgements The authors thank the Medical Writing Center at Children's Mercy Kansas City for editing this manuscript for style and clarity.

Contributors All authors listed on this manuscript have contributed to the following tasks: substantial contributions to the conception or design of the work, or the acquisition, analysis or interpretation of data; drafting the work or revising it critically for important intellectual content; final approval of the version published; and agreement to be accountable for all aspects of the work in ensuring that questions related to the accuracy or integrity of any part of the work are appropriately investigated and resolved.

Funding The authors have not declared a specific grant for this research from any funding agency in the public, commercial or not-for-profit sectors.

Disclaimer The views expressed are solely those of the authors and do not reflect the official policy or position of the US Army, US Navy, US Air Force, the Department of Defense or the US Government.

Competing interests TAR receives research funding for an unrelated project as part of the Merck Pharmaceuticals Investigator Directed Research Programme. JS 
is on active duty with the United States Air Force. DA is an employee of the United States Department of Defense.

Patient and public involvement Patients and/or the public were involved in the design, or conduct, or reporting, or dissemination plans of this research. Refer to the methods section for further details.

Patient consent for publication Not required.

Ethics approval This study was approved by the 59th Medical Wing institutional review board.

Provenance and peer review Not commissioned; externally peer reviewed.

Data availability statement A de-identified copy of the data is available from the corresponding author upon reasonable request.

ORCID iD

Timothy A Roberts http://orcid.org/0000-0003-4966-7079

\section{REFERENCES}

1 Handelsman DJ, Hirschberg AL, Bermon S. Circulating testosterone as the hormonal basis of sex differences in athletic performance. Endocr Rev 2018;39:803-29.

2 Singh B, Singh K, Sharma N. Equality, equity and inclusion: transgender athletes' participation in competitive sports - a new era. Phys Cult Sport Stud Res 2010:49:85-8.

3 Semerjian TZ, Cohen JH. "FTM means female to me": transgender athletes performing gender. Women Sport Phys Act J 2016;15:28-43.

4 Genel M. Transgender athletes: how can they be accommodated? Curr Sports Med Rep 2017;16:12-13.

5 Bianchi A. Transgender women in sport. J Philos Sport 2017;44:229-42.

6 Hartgens F, Kuipers H. Effects of androgenic-anabolic steroids in athletes. Sports Med 2004:34:513-54.

7 Franke WW, Berendonk B. Hormonal doping and androgenization of athletes: a secret program of the German Democratic Republic government. Clin Chem 1997:43:1262-79.

8 Ingram BJ, Thomas CL. Transgender policy in sport, a review of current policy and commentary of the challenges of policy creation. Curr Sports Med Rep 2019;18:239-47.

9 Gooren LJG, Bunck MCM. Transsexuals and competitive sports. Eur J Endocrinol 2004;151:425-9.
10 International Olympic Committee. $10 \mathrm{C}$ consensus meeting on sex reassignment and hyperandrogenism, 2016. Available: http://www.olympic. org/Documents/ Commissions_PDFfiles/Medical_commission/2015-11_ioc_consensus_meeting_on_ sex_reassignment_and_hyperandrogenism-en.pdf [Accessed 30 Dec 2019].

11 Camporesi S. A question of 'fairness': Why ethics should factor in the Court of Arbitration for sport's decision on the IAAF hyperandrogenism regulations. Br J Sports Med 2019;53:797-8.

12 Van Caenegem E, Wierckx K, Taes Y, et al. Bone mass, bone geometry, and body composition in female-to-male transsexual persons after long-term cross-sex hormonal therapy. J Clin Endocrinol Metab 2012:97:2503-11.

13 Van Caenegem E, Wierckx K, Taes Y, et al. Body composition, bone turnover, and bone mass in trans men during testosterone treatment: 1-year follow-up data from a prospective case-controlled study (ENIGI). Eur J Endocrinol 2015;172:163-71.

14 Scharff M, Wiepjes CM, Klaver M, et al. Change in grip strength in trans people and its association with lean body mass and bone density. Endocr Connect 2019;8:1020-8.

15 Lapauw B, Taes Y, Simoens S, et al. Body composition, volumetric and areal bone parameters in male-to-female transsexual persons. Bone 2008;43:1016-21.

16 Van Caenegem E, Wierckx K, Taes Y, et al. Preservation of volumetric bone density and geometry in trans women during cross-sex hormonal therapy: a prospective observational study. Osteoporos Int 2015;26:35-47.

17 Wiik A, Lundberg TR, Rullman E, et al. Muscle strength, size, and composition following 12 months of gender-affirming treatment in transgender individuals. J Clin Endocrinol Metab 2020;105:dgz247:e805-13.

18 Elbers JM, Asscheman H, Seidell JC, et al. Effects of sex steroid hormones on regional fat depots as assessed by magnetic resonance imaging in transsexuals. Am J Physiol 1999:276:E317-25.

19 Mueller A, Zollver H, Kronawitter D, et al. Body composition and bone mineral density in male-to-female transsexuals during cross-sex hormone therapy using gonadotrophin-releasing hormone agonist. Exp Clin Endocrinol Diabetes 2011;119:95-100.

20 Fighera TM, da Silva E, Lindenau JD-R, et al. Impact of cross-sex hormone therapy on bone mineral density and body composition in transwomen. Clin Endocrinol 2018:88:856-62.

21 Harper J. Race times for transgender athletes. Journal of Sporting Cultures and Identities 2015;6:1-9.

22 Griffith JR. The air force fitness test: creating new fitness assessment charts using waist to height ratios (2017). Theses and dissertations. 782. Available: https://scholar. afit.edu/etd/782 [Accessed 29 Apr 2020]. 